\title{
Relating mathematical abilities to numerical skills and executive functions in informal and formal schooling
}

\author{
Peera Wongupparaj ${ }^{*}$ (ID and Roi Cohen Kadosh²
}

\begin{abstract}
Background: The current evidence on an integrative role of the domain-specific early mathematical skills and number-specific executive functions (EFs) from informal to formal schooling and their effect on mathematical abilities is so far unclear. The main objectives of this study were to (i) compare the domain-specific early mathematics, the number-specific EFs, and the mathematical abilities between preschool and primary school children, and (ii) examine the relationship among the domain-specific early mathematics, the number-specific EFs, and the mathematical abilities among preschool and primary school children.

Methods: The current study recruited 6- and 7-year-old children $\left(N_{\text {total }}=505, n_{6 y r s}=238\right.$, and $\left.n_{7 y r s}=267\right)$. The domain-specific early mathematics as measured by symbolic and nonsymbolic tasks, number-specific EFs tasks, and mathematics tasks between these preschool and primary school children were compared. The relationship among domain-specific early mathematics, number-specific EFs, and mathematical abilities among preschool and primary school children was examined. MANOVA and structural equation modeling (SEM) were used to test research hypotheses.
\end{abstract}

Results: The current results showed using MANOVA that primary school children were superior to preschool children over more complex tests of the domain-specific early mathematics; number-specific EFs; mathematical abilities, particularly for more sophisticated numerical knowledge; and number-specific EF components. The SEM revealed that both the domain-specific early numerical and the number-specific EFs significantly related to the mathematical abilities across age groups. Nevertheless, the number comparison test and mental number line of the domain-specific early mathematics significantly correlated with the mathematical abilities of formal school children. These results show the benefits of both the domain-specific early mathematics and the number-specific EFs in mathematical development, especially at the key stages of formal schooling. Understanding the relationship between EFs and early mathematics in improving mathematical achievements could allow a more powerful approach in improving mathematical education at this developmental stage.

Keywords: Domain-specific early mathematics, Number-specific executive functions, Mathematical abilities, Preschool and primary school children

*Correspondence: peera.wo@go.buu.ac.th

${ }^{1}$ Cognitive Science and Innovation Research Unit, College of Research

Methodology and Cognitive Science, Burapha University, Saen Suk,

Thailand

Full list of author information is available at the end of the article

\section{Introduction}

Mathematical skills are regarded as an important tool and an integral part of effective functioning in everyday life $[1,2]$. These skills are the keys to analyzing and interpreting information and also making basic or complex decisions [3]. Meanwhile, several lines of evidence show

(c) The Author(s) 2022. Open Access This article is licensed under a Creative Commons Attribution 4.0 International License, which permits use, sharing, adaptation, distribution and reproduction in any medium or format, as long as you give appropriate credit to the original author(s) and the source, provide a link to the Creative Commons licence, and indicate if changes were made. The images or other third party material in this article are included in the article's Creative Commons licence, unless indicated otherwise in a credit line to the material. If material is not included in the article's Creative Commons licence and your intended use is not permitted by statutory regulation or exceeds the permitted use, you will need to obtain permission directly from the copyright holder. To view a copy of this licence, visit http://creativecommons.org/licenses/by/4.0/. The Creative Commons Public Domain Dedication waiver (http://creativeco mmons.org/publicdomain/zero/1.0/) applies to the data made available in this article, unless otherwise stated in a credit line to the data. 
that early mathematics achievement might predict a person's professional success and economic growth $[4,5]$. Understanding these developmental trajectories and cognitive underpinnings is essential because of the promising predictability of later positive outcomes as a result of early numerical abilities.

Researchers from several disciplines have currently begun to reveal underlying cognitive and brain architectures of our numerical processing abilities (e.g., [6-11]). One theoretical perspective explains the diversity in early numerical ability by referring to the development of the domain-specific approach. The theory states that early numerical abilities and difficulties are closely related to numerical core systems (i.e., the approximate number system [ANS]; [12, 13]). Typically, several studies on infants and young children suggested progressive acquisitions of numerical development [14-16], where the ANS nonsymbolic and symbolic numerical magnitude processing abilities (as indexed by dot-dot and dot-number comparison and a mental number line tests) were assumed to form the basis of numerical skills among preschoolers who had not yet been taught a formal mathematics lesson [12]. A more accurate ANS or symbolic magnitude comparison ability (e.g., a number comparison test) and symbolic magnitude estimation ability (e.g., the mental number line test) were later developed [17, 18]. This continuing numerical ability uses the prenumerical ANS and is also being thought of as the numerical development from subitizing, counting, and estimating to arithmetic [16]. These early numerical systems have also been called the "core-systems of number" [12].

Other studies have also alternatively revealed the main roles of executive functions (EFs) [19] as a crucial predictor of early numerical abilities. This domain-general theoretical framework proposes that symbolic numerical magnitude estimation ability, as measured by the mental number line test, may need more than complete core systems of number [20,21]. It has been proposed that this process includes broad cognitive processes, such as EFs, that work together with numerical processing to influence numerical development throughout childhood [22]. EFs in early childhood show significant improvements after age 5 , demonstrated in abilities such as shifting (cognitive flexibility), inhibition of dominant or prepotent responses, and updating of working memory [23-26]. The majority of the research suggests that domain-general skills contribute to early numerical development, especially during the transition from preschool to kindergarten [27, 28]. Nonetheless, several contradictory results on the contribution of domain-general abilities to numerical development and the processes driving their integration remain uncertain. [29]. Specifically, the how, why, and what components of EFs in numerical context are essential and whether or not EFs are genuinely malleable to leverage early mathematical development from informal to formal schooling [30, 31].

A multicomponent framework of mathematics highlighting the main role of EFs on domain-specific numerical skills and early numerical abilities as being an indirect and stable relationship from age 8 years through to young adults has been documented [31]. This study did not capture the early stage of informal mathematical growth. The unique contributions of either the general EFs or EFs in numerical contexts on domain-specific numerical skills and early numerical abilities across age groups are also unclear [32]. A recent study found that general EFs skills did not affect mathematics achievement across age and grade (preschool-fourth grade) [33], but a recent longitudinal finding suggested that only EFs in a numerical context were far more important than ANS or general EFs to predict developmental dyscalculia and numerical accomplishment [34]. This finding is consistent with prior research that discovered a significant contribution of EFs-related numerical, but not non-numerical, content to mathematical abilities in 93 children [35]. Further, only EFs in numerical context, beyond general EFs, could predict developmental dyscalculia and mathematics achievement from ages 4 to 13 [34].

More specifically, the general EFs or EFs in numerical contexts may consist of partially dissociable components in early childhood [36-40]. The numerical specific EFs or EFs in numerical contexts have a stronger link to children's math growth over and above the general EFs [40] because children's ability to attend to numerical and spatial magnitudes involving in mathematics achievement may differ from those of music activities or reading counting books [41].

Several studies demonstrated the significant connection among specific executive functioning, that is, working memory, inhibition and shifting abilities, and mathematical ability in children [35, 42]. Inhibitory control is required to inhibit a dominant or irrelevant response [43]. Working memory refers to the ability to hold, update, and manipulate information within memory storage $[25,43]$. Shifting ability is the ability to switch attention between tasks, mental sets, and strategies or the ability to flexibly disengage or engage with specific parts within tasks $[25,39]$. Nonetheless, the relationship between EF components and mathematical competencies in early childhood may depend on some aspects of EF and specific mathematical concepts (i.e., early numeracy, counting, conceptual, and procedural skills) [44, 45].

The developmental patterns for the relationship between inhibitory control and shifting/switching abilities with mathematics achievement differed depending on the academic outcomes examined [46]. That is, 
few developmental changes were shown in the connection between EF components and mathematical abilities across elementary schools [42]. The unique contribution of EF components on mathematics outcome has also not been fully understood because the key roles of EF components on mathematics achievement were discovered, particularly for older students [47]. There is little research that highlights the interface of emerging and specific EF components and early mathematical learning in preschool children beyond numeracy and counting to emergent and critical mathematical proficiency in primary school children $[45,48]$. These works have mainly relied on general EF assessment even though extensive research has been carried out in young children on the EF components and mathematics achievement in several contexts $[42,49,50]$.

Although recent literature support transfer effects from EF interventions to mathematical abilities, the EF trainings have a larger effect in preschool than in school ages [51-53]. Further, some studies suggested ineffective transfers from EF trainings to mathematics outcomes $[50,54]$. It is possibly suggested that previous approaches might fail to consider the specific ways in which EF is related to mathematics [55]. The lack of training transfer could stem from the fact that number-specific EFs are more significantly correlated with mathematical abilities than EFs measured by tasks that do not involve numerically relevant stimuli $[34,56-58]$. Taken together, these pieces of information appear to imply that the heterogeneity of general EF measures may mask the relationship between EF components and mathematical achievement $[46,56]$. Therefore, the EFs-numerical contexts tasks should be emphasized and used to investigate the complex relationship between specific components of the EFs and mathematics achievement.

It can be concluded that several studies have focused on numerical and domain-general executive functioning skills $[59,60]$. The primary functions of the domain-specific early mathematical skills (i.e., ANS) and number-specific EFs (i.e., EFs in numerical contexts) from informal to formal schooling are relatively scarce. Such knowledge could shed light on the development of mathematical achievement in that the number-specific EF was conceptualized as the main underlying processes or mechanisms for driving the domain-specific early mathematics across the development of numerical cognition in children. The current investigation aimed to (a) compare the domain-specific early mathematics, the number-specific EFs, and the mathematical abilities between preschool and primary school children and (b) examine the relationship among the domain-specific early mathematics, the number-specific EFs, and the mathematical abilities among preschool and primary school children.
Structural equation modeling (SEM) was employed to test the direct and indirect effects of the domain-specific early mathematics and number-specific EFs on mathematical abilities among preschool [6 years old] and primary school (7 years old) children. Domain-specific early mathematics were categorized by the dot-dot comparison, the dot-number comparison, the number comparison, and the mental number line tests. Number-specific EFs were represented by the numerical inhibitory and the numerical shifting tests. Formal and informal mathematical abilities were measured by the number sets [61] and the numerical operation tests (Fig. 1).

\section{Methods \\ Participants}

The current study included 511 6- to 7-year-old children (238 or $47.1 \%$ for 6-year-old preschoolers and 267 or $52.9 \%$ for 7 -year-old first graders); six children were excluded because of missing values, thus leaving 505 children (50.2\% female participants) for final analysis. All participants were native Thai and attended 12 public schools in Chonburi province, Thailand and a sample of 12 public schools was drawn using a stratified sampling technique. All public schools used the same set of subjects and standards under the national curriculum for Thailand. The preschoolers and first graders were studying at the same public schools with equal proportions. No participant was clinically referred for learning difficulties (LD) or attention-deficit/hyperactivity disorder (ADHD). The experimental protocols were approved by the Burapha University Research Ethics Committee (BUU 6200/01533). All methods were carried out in accordance with the Good Clinical Practice (GCP) guidelines and the Declaration of Helsinki. Written informed consent was obtained from parents of all participants prior to inclusion.

\section{Measures}

The domain-specific early mathematics is composed of eight paper-and-pencil tests (the dot-dot comparison test, the dot-number comparison test, the number comparison test [also termed symbolic magnitude processing test [1], and the mental number line], the number-specific EFs (numerical inhibitory and shifting tests), and the mathematical abilities (number sets and numerical operation tests). These domain-specific early mathematics assessments were developed to tap into distinct aspects of young children's mathematics development that are considered to be essential in preschool and primary school mathematics $[18,20]$. The number-specific EFs measures were used to reflect common and specific aspects of EFs in numerical contexts [62]. These tests were chosen to fit best with the age range tested in the 
(A)

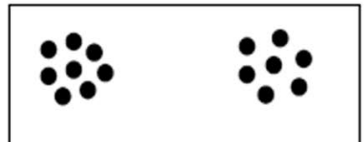

(B)

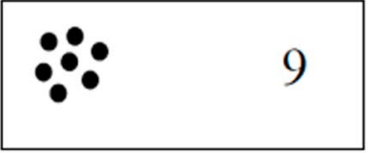

(D)

6

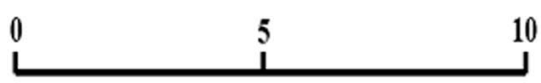

2

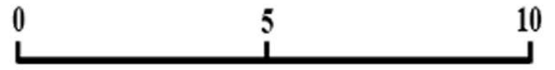

(F)
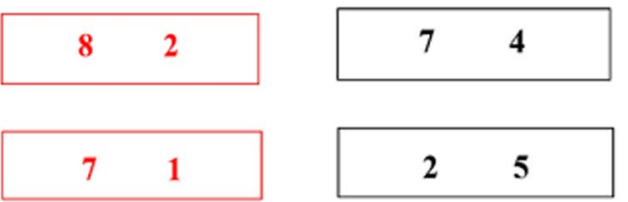
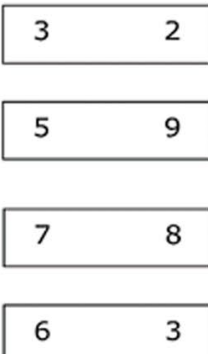

3

(E)
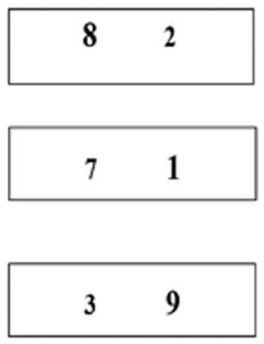

46

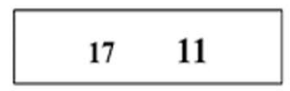

(C)

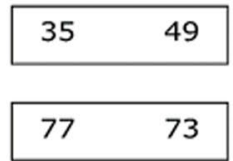

\section{$31 \quad 18$}

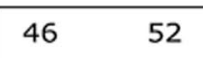

$88 \quad 94$

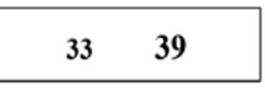

$34 \quad 28$

(H)

4
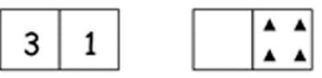

(G)

\begin{tabular}{|c|c|}
\hline 3 & 12 \\
+1 & - \\
1 & 3 \\
- & + \\
2 & 3 \\
\hline$=$ & $=$ \\
\hline
\end{tabular}

Fig. 1 Screenshots of the tests in the current study: A The dot-dot comparison test; $\mathbf{B}$ The dot-number comparison test; $\mathbf{C}$ The number comparison test; $\mathbf{D}$ The mental number line; $\mathbf{E}$ The numerical Stroop test; $\mathbf{F}$ The numerical shifting test; $\mathbf{H}$ The number sets test; $\mathbf{G}$ The numerical operation test 
current study and fit the emerging literature on the structure of EFs in the preschool and primary school periods $[56,58,63]$.

The number sets and numerical operation tests were selected to index the mathematical abilities because these measures were used to reflect different mathematical skills rather than mathematics achievement in a single multicomponent standardized test $[61,64]$. The number sets test was designed to assess a small area of early numeracy or "number sense" and fluency in identifying and processing quantities indexed by object sets and numerals $[61,65]$, whereas the numerical operation test was used to measure basic arithmetic skills or "arithmetic fact" in line with the national curriculum for preschool and primary school levels. These tests were administered in quiet rooms that were provided by the schools, and a group-administered test was used for all children at their schools. All children were not allowed to count and/or take notes, and these behaviors were monitored by researchers. The constructs, tests, test lengths, and time spent are shown in Table 1. All children were assessed across eight tests, and the test administration took approximately $33 \mathrm{~min}$ for each child.

\section{The dot-dot comparison test}

The dot-dot comparison test was used to assess the enumerating ability by comparing two sets of dots that reflect subitizing and counting systems of children's early numerical abilities [66]. The dot-dot comparison test is composed of 30 items, and each item contains two sets of black dots with a pseudorandom arrangement on a white background (see Fig. 1A). The average distance between the centers of the two black-dot sets was $2.93 \mathrm{~cm}$ (minimum $=2.80 \mathrm{~cm}$ and maximum $=3.0 \mathrm{~cm}$ ). Each dot was equated in size $(0.30 \mathrm{~cm}$ in diameter), each group of dots was also comparable in size $(1.00 \mathrm{~cm}$ in diameter), and numerosity (several dots from 1 to 9) differed across items. All children were instructed to circle which set of dots contained more dots without counting as accurately and quickly as possible within $2.5 \mathrm{~min}$. A response was scored as correct ( 1 point) and incorrect ( 0 point) with a range of scores between 0 and 30 . The correct answer for each item was counterbalanced, and no more than three consecutive right answers on the same side were shown [1]. The Kuder-Richardson (KR)-20 reliability coefficient of this test was 0.97 .

\section{The dot-number comparison test}

The dot-number comparison test was used to assess the numerical ability in associating and comparing a perceived number of objects (dots) with Arabic numerals (nonsymbolic vs. symbolic numbers). An Arabic symbolization is required for the development of the mental number line as a representation of magnitude and ordinality to visual space [67]. The dot-number comparison test contained 30 items, and each item contains two different sets of black dots and a single digit presenting on a white background with a pseudorandom arrangement on the left side and the single digit on the right side (see Fig. 1B). The mean distance between the centers of the dot-number pairs was $2.99 \mathrm{~cm}$ (minimum $=2.9 \mathrm{~cm}$ and maximum $=3.2 \mathrm{~cm}$ ). All dots were equated in size $(0.3 \mathrm{~cm}$ in diameter), each group of dots was also equal in size $(1 \mathrm{~cm})$, and several dots ranged from 1 to 9 . All the single digits were displayed in 20-point Times New Roman font. All children were instructed to circle which of the two sets between the dot-number pair is larger without counting as accurately and quickly as possible within $2.5 \mathrm{~min}$. A response was scored as correct ( 1 point) and incorrect ( 0 point) with a range of scores

Table 1 The constructs, tests, test length, and time spent

\begin{tabular}{|c|c|c|c|c|}
\hline Constructs & & Tests & Number of items & $\begin{array}{l}\text { Time } \\
\text { spent } \\
\text { (min) }\end{array}$ \\
\hline \multirow{4}{*}{$\begin{array}{l}\text { The domain-specific early } \\
\text { mathematics }\end{array}$} & Dot-Dot comparison & Dot-Dot comparison test & 30 & 2.5 \\
\hline & Dot-Number comparison & Dot-Number comparison test & 30 & 2.5 \\
\hline & Number comparison & $\begin{array}{l}\text { Number comparison test } \\
\text { (Single \& Double digits) }\end{array}$ & $\begin{array}{l}60 \text { (Single) } \\
60 \text { (Double) }\end{array}$ & $\begin{array}{l}2 \\
3\end{array}$ \\
\hline & Analogous Magnitude representation & $\begin{array}{l}\text { Mental number line: Percent Abso- } \\
\text { lute Error }\end{array}$ & 10 & 5 \\
\hline \multirow[t]{2}{*}{ The number-specific EFs } & Inhibition & $\begin{array}{l}\text { Numerical Stroop test } \\
\text { (Single \& Double digits) }\end{array}$ & $\begin{array}{l}30 \text { (Single) } \\
30 \text { (Double) }\end{array}$ & $\begin{array}{l}2 \\
3\end{array}$ \\
\hline & Shifting & Numerical shifting test & 35 & 3 \\
\hline \multirow[t]{2}{*}{ Mathematical abilities } & & Number sets test & $\begin{array}{l}16 \text { (5 set) } \\
16 \text { (9 set) }\end{array}$ & $\begin{array}{l}2 \\
3\end{array}$ \\
\hline & & Numerical operation test & 20 & 5 \\
\hline
\end{tabular}


between 0 and 30 . The correct answer for each item was also counterbalanced, and no more than three successive correct answers on the same side were shown [1]. The KR-20 reliability coefficient of this test was 0.97 .

\section{The number comparison test}

The number comparison test was used to examine symbolic numerical magnitudes [1]. The number comparison test is composed of two numerical magnitude comparison subtests: a single-digit subtest with digits ranging from 1 to 9 and a two-digit subtest with digits between 11 and 99. The 120-digit pairs (60 pairs for single and 60 pairs for two-digit subtests) were displayed in four columns of 15 pairs in a 12-point Verdana font for each subtest (see Fig. 1C). The number pairs were randomly presented, and four factors were taken into account: (1) a counterbalance of the correct answer on the side in each column, (2) different numbers in subsequent or neighboring number pairs, (3) no more than three consecutive correct answers presenting on the same side, and (4) no similar or inverse number pairs (e.g., 6-2 vs. 2-6) presenting in the same row or column. All children were instructed to circle the larger of the single or two-number pairs as accurately and quickly as possible within 2 and 3 min for single- and two-digit subtests. A response was also scored as correct ( 1 point) and incorrect ( 0 point) with a range of scores between 0 and 60 for both singleand two-digit subtests. The KR-20 reliability coefficient of this test was 0.99 for the single-digit subtest, 0.98 for the two-digit subtest, and 0.99 for the overall numerical comparison test.

\section{The mental number line test}

The mental number line test was used to assess proficiency in numerical magnitude processes and representations [68]. The mental number line test contained 10 items, and all children were instructed to estimate by crossing out a location of 10 target numbers on $13-\mathrm{cm}$ number lines. Each horizontal number line started with a target number and a 0 at the left endpoint and numbers (i.e., 10, 20, 50, and 100) at the right endpoint (see Fig. 1D). All digits were displayed in a 12-point and 16-point Times New Roman font for target numbers and anchored numbers at the left and right endpoints of the mental number line test, respectively. They were instructed to complete the test as accurately and quickly as possible within $5 \mathrm{~min}$. A response was scored in line with the percent absolute error (PAE) formula [21] and was defined as the absolute difference between target number and children's estimate divided by the scale of each item and expressed as a percentage (i.e., |target number-participant's estimated number|]/numerical range) $\times 100$. The PAE scores ranged from 0 to $100 \%$, and a higher PAE score indicated a less accurate series of estimates. The internal consistency with Cronbach's $\alpha$ was 0.77 .

\section{The numerical inhibition test}

The numerical inhibition test was used to assess a cognitive inhibition or the ability to automatically inhibit irrelevant responses and adjust control [69-71] on physical and numerical pairs. The numerical inhibition test contained two subscales, that is, a one-digit subtest with digits ranging from 1 to 9 and a two-digit subtest with digits ranging from 11 to 99 . The 60-digit pairs (30 pairs for single and 30 pairs for two-digit subtests) were displayed in three columns of 10 pairs in 22-point and 26-point Times New Roman font for smaller and larger physical sizes. The distances between two digits of each number pair were six, four, and two for the first, second, and third columns, respectively (e.g., 1 7, 2 6, and 3 5; see Fig. 1E). The number pairs were randomly shown, and four factors were also taken into consideration: (1) a counterbalance of the right answer on the side in each column, (2) different numbers in subsequent or neighboring number pairs, (3) no more than three consecutive correct answers showing on the same side, and (4) no similar or inverse number pairs (e.g., 15 vs. 51 ) presenting in the same row or column. All children were instructed to compare the physical sizes of two numbers and circle the larger of the single or two-number pairs as accurately and quickly as possible within 2 and 3 min for single- and two-digit subtests. A response was scored as correct (1 point) and incorrect ( 0 point) with a range of scores between 0 and 30 for both single- and two-digit subtests. The KR-20 reliability coefficient of this test was 0.98 for the singledigit subtest, 0.95 for the two-digit subtest, and 0.98 for the overall test.

\section{The numerical shifting test}

The numerical shifting test was used to assess children's cognitive flexibility performance or the ability to shift attention on the basis of changing (numerical) condition demands [72]. The paper-and-pencil version for the children was adapted from the computerized switching task by modifying the procedures and stimuli [73, 74]. The numerical shifting test contained 36 items with digit pairs ranging from 1 to 9 . The 36-digit pairs were showed in three columns of 12 pairs in 26-point Times New Roman font for each column. The digit pairs were displayed in red or black: the red digit pairs signaled to the children that it was a greater-than-five condition and the black digit pairs indicated that it was an odd-even condition. Each column is composed of three-set shifts between greater-than-five and odd-even conditions (see Fig. 1F). The number pairs were randomly displayed, 
and four factors were also taken into consideration: (1) a counterbalance of the correct answer on the side in each column, (2) different numbers in subsequent or neighboring number pairs, (3) no more than three consecutive correct answers showing on the same side, and (4) no similar or inverse number pairs (e.g., 52 vs. 2 5) presenting in the same row or column. All children were instructed to decide which red digit is greater than five and which black digit is odd or even as accurately and quickly as possible within $3 \mathrm{~min}$. A response was scored as correct ( 1 point) and incorrect ( 0 point) with a range of scores between 0 and 36 . The KR-20 reliability coefficient of this test was 0.95 .

\section{The number sets test}

The number sets test was used to assess mathematical abilities in young children [64]. The number sets test is composed of 32 items with 16 items for each target number: "five" and "nine." Each item contained a pair or trio of Arabic numbers with an 18-point font in a half-inch square, object sets (stars, circles, diamonds, and triangles) in a half-inch square, or both of them, and the Arabic numbers and object sets were combined to create domino-like rectangles (see Fig. 1G and further details in a previous study [61]). All children were instructed to circle any groups that can be put together to make the number at the top of the page, which could be 5 or 9 , and to complete as quickly as possible within 2 and $3 \mathrm{~min}$ for the targets " 5 " and "9", respectively. A response was scored as correct ( 1 point) and incorrect ( 0 point) with a range of scores between 0 and 16 for the targets " 5 " and "9" and between 0 and 32 for both targets. The KR-20 reliability coefficient for the targets " 5 " and "9" were 0.94 and 0.95 and 0.96 for both targets.

\section{The numerical operation test}

The numerical operation test was adapted and used to assess children's storage and manipulation of numerical operations $[75,76]$. This test was also called "arithmetic facts" in the literature, but it included only addition and subtraction in basic forms. The test items were reviewed, and all items were consistent with education and curriculum in preschool and primary school levels. The numerical operation test is composed of 20 items: 8 items for single-digit numerical operations and 12 items for double-digit numerical operations. The 20 items of numerical operations were shown in four columns in 22-point Times New Roman font for each column (see Fig. 1H). All children were only asked to write down the answer as the outcome of numerical operations such as adding and carrying. A response was scored as correct (1 point) and incorrect ( 0 point) with a range of scores between 0 and 20. The KR-20 reliability coefficient of this test was 0.95 .

\section{Statistical analysis}

MANOVA was used to evaluate the age group differences between preschool (6 years old) and primary school (7 years old) children across eight dependent variables to answer the research questions and test the research hypotheses. The partial $\eta^{2}$ was also calculated to represent the magnitude of difference between groups $[77,78]$. The first latent variable for domain-specific early mathematics was obtained from four observed variables, that is, dot-dot, dot-number, number comparison, and mental number line, and the second latent variable for number-specific EFs was generated from two observed variables, namely numerical inhibition and shifting, in measurement and structural models. The third variable for the mathematical abilities was also derived from two observed variables, that is, the number sets and the numerical operation. Finally, the direct paths among the first latent variable, the second latent variable, and the third latent variable were estimated.

No missing value was found for the current study. Data analyses were carried out using IBM SPSS statistics for Window, version 26 (IBM Corp., Armonk, NY, USA) and SPSS Amos version 26.0 [79-81]. The structural equation model (SEM) parameters were estimated by using the maximum likelihood procedure. The goodness-of-fit indices of the estimated models were evaluated using five indicators, that is, the $p$ value of chi-square $\left(\chi^{2}\right)$ above 0.05 and $\chi^{2} / d f$ smaller than 3 are preferred, the $p$ value of root mean square error of approximation (RMSEA) lower than 0.07 indicates a well-fitting model, the comparative fit index (CFI), the goodness of fit index (GFI), and the adjusted GFI; the values over 0.90 suggest a good fit $[82,83]$. The models for the overall pooled, 6-year-old, and 7-year-old children supported the empirical data and provided good model fits, the $\mathrm{p}$ values of $\chi^{2}=0.93,0.05$, and $0.57 ; \chi^{2} / d f=0.93,1.97$, and 0.83; RMSEA $=<0.05$, 0.06 , and $<0.01$; $\mathrm{CFI}=1.00,0.99$, and 1.00; $\mathrm{GFI}=1.00$, 0.98, and 0.99; Adjusted GFI $=0.98,0.93$, and 0.97, respectively.

\section{Results \\ Descriptive statistics, group difference, and correlation coefficients among variables}

Table 2 shows the domain-specific early mathematics represented by four variables, that is, dot-dot, dotnumber, number comparison, and mental number line. The number-specific EFs were indexed by two variables, namely, numerical inhibition and shifting. The mathematical abilities were also represented by two variables, that is, the number sets and the numerical operation. In general, the domain-specific early mathematics of 6-yearold children was significantly lower than that of 7-yearold children, but it was clearly shown for the number 
Table 2 Descriptive statistics for variables indicating the domain-specific early mathematics, the number-specific EFs and the mathematical abilities among 6-and 7-year-old children $\left(n_{6 y r s}=238 / n_{7 y r s}=267 / N_{\text {overall }}=505\right)$ and age group differences

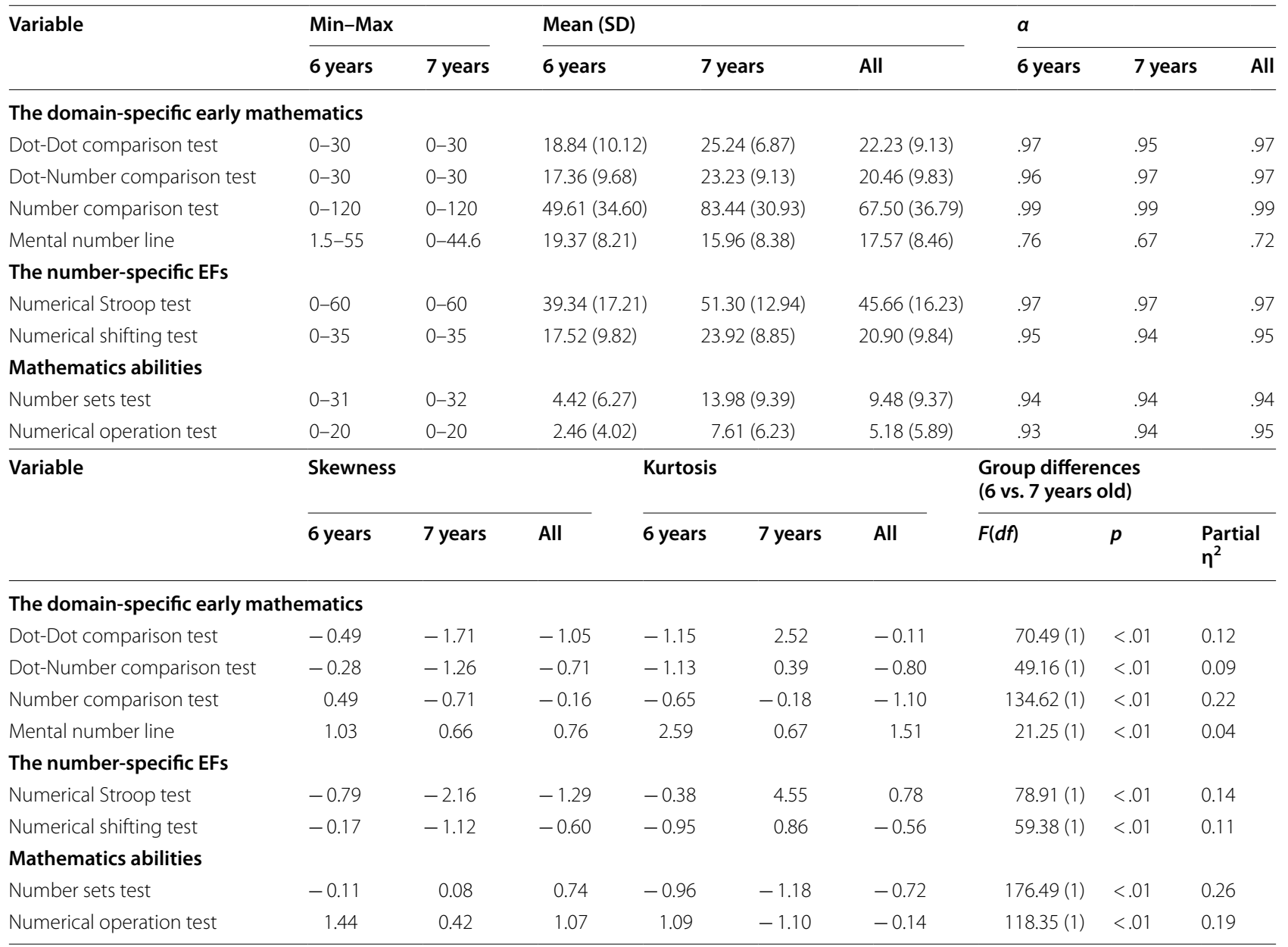

comparison test that the 6-year-old children had a lower score on the number comparison test with a large effect size than that of the 7-year-old children. Similarly, the number-specific EFs for 7-year-old children were higher; however, the effect sizes for all variables in the numberspecific EFs between two age groups were moderate. The mathematical abilities were better for 7-year-old children, and a strong effect size was observed.

The coefficient alpha $(\alpha)$ for all measures was generally excellent $(\alpha \geq 0.90)$, but it was only acceptable for the mental numbe line test $(\alpha=0.76)$. All variables were normally distributed, as measured by skewness and kurtosis (see Table 2). Table 3 shows the correlation coefficients among variables representing the domainspecific early mathematics, the number-specific EFs, and the mathematical abilities for the overall pooled children $(N=505)$ broadly demonstrating a moderate relationship, that is, the correlations between variables in the domain-specific early mathematics, the numberspecific EFs, and the mathematical abilities ranged from -0.43 to 0.64 for the number sets. Table 4 shows a moderate correlation between variables reflecting the domain-specific early mathematics, and the numberspecific EFs and the number sets $(-0.30$ to 0.51$)$ and the numerical operation $(-0.31$ to 0.51$)$ were observed for 6-year-old children. A weak-to-moderate connection, on the other hand, was identified between variables indexing domain-specific early mathematics and number-specific EFs and the number sets (0.34 to 0.54) and the numerical operation (0.29 to 0.51$)$ for 7-yearold children. The multicollinearity tests were performed using the value inflation factor (VIF), and all VIF scores for pooled children, for 6-year-old children, and for 7-year-old children were less than the threshold of 5 , indicating that the multicollinearity is not a problem in current datasets [83]. 
Table 3 The correlation coefficients among variables representing the domain-specific early mathematics, the number-specific EFs, and the mathematics abilities for the overall pooled children $(\mathrm{N}=505)$

\begin{tabular}{|c|c|c|c|c|c|c|c|c|}
\hline Variable & $\begin{array}{l}\text { Dot-Dot } \\
\text { comparison } \\
\text { test }\end{array}$ & $\begin{array}{l}\text { Dot-Number } \\
\text { comparison } \\
\text { test }\end{array}$ & $\begin{array}{l}\text { Number } \\
\text { comparison } \\
\text { test }\end{array}$ & $\begin{array}{l}\text { Mental } \\
\text { number } \\
\text { line }\end{array}$ & $\begin{array}{l}\text { Numerical } \\
\text { Stroop test }\end{array}$ & $\begin{array}{l}\text { Numerical } \\
\text { shifting } \\
\text { test }\end{array}$ & $\begin{array}{l}\text { Number } \\
\text { sets test }\end{array}$ & $\begin{array}{l}\text { Numerical } \\
\text { operation } \\
\text { test }\end{array}$ \\
\hline \multicolumn{9}{|c|}{ The domain-specific early mathematics } \\
\hline \multicolumn{9}{|c|}{ Dot-Dot comparison test } \\
\hline Dot-Number comparison test & $.61^{* *}$ & & & & & & & \\
\hline Number comparison test & $.66^{* *}$ & $.70^{* *}$ & & & & & & \\
\hline Mental number line & $-.26^{* *}$ & $-.30^{* *}$ & $-.40^{* *}$ & & & & & \\
\hline \multicolumn{9}{|l|}{ The number-specific EF } \\
\hline Numerical Stroop test & $.64^{* *}$ & $.58^{* *}$ & $.70^{* *}$ & $-.31^{* *}$ & & & & \\
\hline Numerical shifting test & $.47^{* *}$ & $.50^{* *}$ & $.59^{* *}$ & $-.24^{* *}$ & $.58^{* *}$ & & & \\
\hline \multicolumn{9}{|l|}{ Mathematics ability } \\
\hline Number sets test & $.45^{* *}$ & $.48^{* *}$ & $.64^{* *}$ & $-.43^{* *}$ & $.50^{* *}$ & $.48^{* *}$ & & \\
\hline Numerical operation test & $.42^{* *}$ & $.40^{* *}$ & $.60^{* *}$ & $-.44^{* *}$ & $.44^{* *}$ & $.39^{* *}$ & $.61^{* *}$ & \\
\hline
\end{tabular}

** $p<.001$

Table 4 The correlation coefficients among variables representing the domain-specific early mathematics, the number-specific EFs, and the mathematical abilities for the overall pooled children for 6- (lower diagonal) and 7- (upper diagonal) year-old children (ns $=238$ and 267)

\begin{tabular}{|c|c|c|c|c|c|c|c|c|}
\hline Variable & $\begin{array}{l}\text { Dot-Dot } \\
\text { comparison } \\
\text { test }\end{array}$ & $\begin{array}{l}\text { Dot-Number } \\
\text { comparison } \\
\text { test }\end{array}$ & $\begin{array}{l}\text { Number } \\
\text { comparison } \\
\text { test }\end{array}$ & $\begin{array}{l}\text { Mental } \\
\text { number } \\
\text { line }\end{array}$ & $\begin{array}{l}\text { Numerical } \\
\text { Stroop test }\end{array}$ & $\begin{array}{l}\text { Numerical } \\
\text { shifting } \\
\text { test }\end{array}$ & Number sets test & $\begin{array}{l}\text { Numerical } \\
\text { operation } \\
\text { test }\end{array}$ \\
\hline \multicolumn{9}{|c|}{ The domain-specific early mathematics } \\
\hline Dot-Dot comparison test & & $.35^{* *}$ & $.47^{* *}$ & $-.20^{* *}$ & $.49^{* *}$ & $.25 * *$ & $.34^{* *}$ & $.29 * *$ \\
\hline $\begin{array}{l}\text { Dot-Number comparison } \\
\text { test }\end{array}$ & $.74^{* *}$ & & $.63^{* *}$ & $-.22^{* *}$ & $.37^{* *}$ & $.44^{* *}$ & $.37^{* *}$ & $.28^{* *}$ \\
\hline Number comparison test & $.68^{* *}$ & $.69^{* *}$ & & $-.35^{* *}$ & $.63^{* *}$ & $.50^{* *}$ & $.54^{* *}$ & $.51^{* *}$ \\
\hline Mental number line & $-.22^{* *}$ & $-.29 * *$ & $-.36^{* *}$ & & $-.30^{* *}$ & $-.20^{* *}$ & $-.44^{* *}$ & $-.44^{* *}$ \\
\hline \multicolumn{9}{|c|}{ The number-specific EF } \\
\hline Numerical Stroop test & $.65^{* *}$ & $.66^{* *}$ & $.65^{* *}$ & $-.23 * *$ & & $.42^{* *}$ & $.40^{* *}$ & $.35^{* *}$ \\
\hline Numerical shifting test & $.51^{* *}$ & $.45^{* *}$ & $.55^{* *}$ & $-.18^{* *}$ & $.61^{* *}$ & & $.36^{* *}$ & $.29 * *$ \\
\hline \multicolumn{9}{|l|}{ Mathematics ability } \\
\hline Number sets test & $.44^{* *}$ & $.49^{* *}$ & $.51^{* *}$ & $-.30^{* *}$ & $.44^{* *}$ & $.49^{* *}$ & & $.43^{* *}$ \\
\hline Numerical operation test & $.43^{* *}$ & $.44^{* *}$ & $.51^{* *}$ & $-.31^{* *}$ & $.39^{* *}$ & $.34^{* *}$ & $.49^{* *}$ & \\
\hline
\end{tabular}

${ }^{* *} p<.001$

SEM analyses to test the relationship among 6-year-old children ( $n=238)$, 7-year-old children $(n=267)$, and the overall pooled children $(\mathrm{N}=505)$

For the SEM model of 6-year old children, the dot-dot, dot-number, and number comparison tests exerted comparable effects $(\beta=0.85, p<0.01 ; \beta=0.85, p<0.01$; $\beta=0.80, p<0.01$, respectively) on the domain-specific early mathematics, but the mental number line showed the lowest factor loading $(\beta=-0.30, p<0.01)$ on the given latent variable. Further, the numercal Stroop and the numerical shifting tests also showed similar effects $(\beta=0.79, p<0.01 ; \beta=0.75, p<0.01$, respectively) on the number-specific EFs latent variable. Both latent variables significantly and positively related $(\beta=0.67, p<0.01$; $\beta=0.69, p<0.01)$ to the mathematical abilities factor as measured by the number sets and the numerical operation tests.

For the SEM model of 7-year old children, the number comparison test showed the strongest factor loading on the domain-specific early mathematics $(\beta=0.94$, $p<0.01)$, followed by the dot-number comparison $(\beta=0.67, p<0.01)$, and the dot-dot comparison tests $(\beta=0.51, p<0.01)$, respectively. However, the mental number line demonstrated the lowest factor loading 
$(\beta=-0.37, p<0.01)$ on the given latent variable in comparison to other factor loadings in measurement model. Hence, the numerical inhibition and shifting showed comparable effects $(\beta=0.67, p<0.01 ; \beta=0.62$, $p<0.01$, respectively) on the number-specific EFs latent variable. Both latent variables also significantly and positively related $(\beta=0.76, p<0.01 ; \beta=0.77, p<0.01)$ to the mathematical abilities factor as measured by the number sets and the numerical operation tests.

For the SEM model of the overall pooled children, the number comparison test showed the strongest factor loading $(\beta=0.97, p<.01)$ on the domain-specific early mathematics, followed by the dot-number comparison $(\beta=0.71, p<0.01)$, and the dot-dot comparison tests $(\beta=0.67, p<0.01)$, respectively. Nonetheless, the mental number line showed the weakest factor loading on the given latent variable $(\beta=-0.41, p<0.01)$. Hence, the numerical inhibition and shifting showed comparable effects $(\beta=0.79, p<0.01 ; \beta=0.74, p<0.01)$ on the number-specific EFs latent variable. Both latent variables also significantly and positively related $(\beta=0.81$, $p<0.01 ; \beta=0.77, p<0.01)$ to the mathematical abilities factor as measured by the number sets and the numerical operation tests (see Fig. 2).

\section{Discussion}

The current study aims to compare and examine the effects of the domain-specific early mathematics and the number-specific EFs on the mathematical abilities in a sample of 6- and 7-year-old children. Analyses were first carried out to test the age group differences across eight dependent variables and to examine the relationships between two latent variables (i.e., the domain-specific early mathematics and the number-specific EFs) and the latent mathematical abilities in a sample of 6- and 7-yearold children.

It can be inferred from the current results that 6- and 7-year-old children (informal schooling and formal schooling) were evident on the number comparison, the number sets, and the numerical operation differences. The finding in itself shows an integrative role of numerical development among numerical comparison, storage, and manipulation abilities on mathematical achievement from preschool to primary school students [75]. The distinctive competency for the number comparison, the numerical operation, and the number sets between two age groups also suggests numerical and developmental acquisitions from understanding precise magnitudes of nonsymbolic numbers, relating nonsymbolic to a foundation of symbolic numerical representations in six-year-olds [84], to expanding

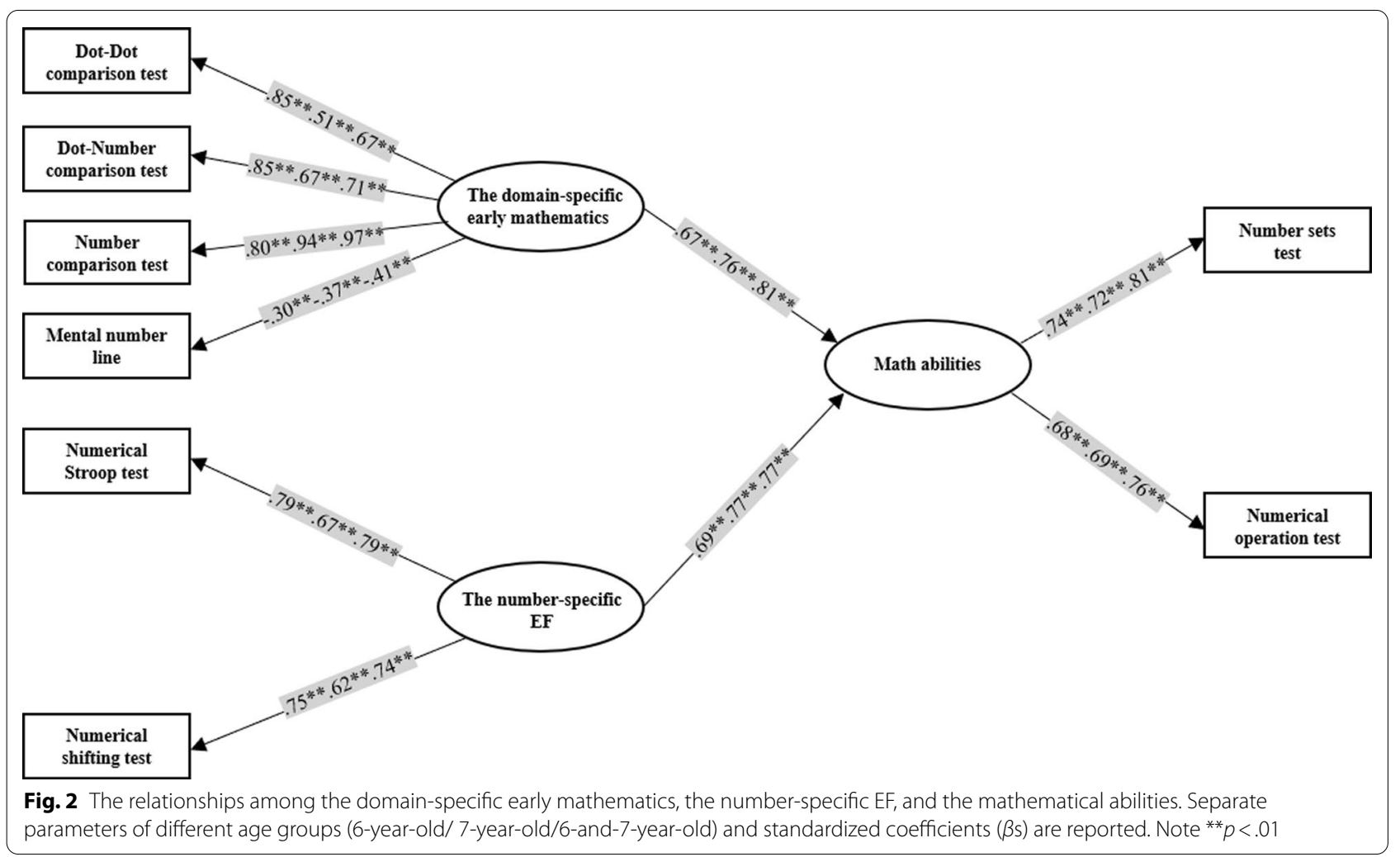


understanding the small symbolic numbers to larger whole numbers (i.e., single and double digits) in 7-yearolds [16].

The dot-dot and dot-number comparison tests were used to examine the process of attributing numerical magnitude to nonsymbolic numbers in both age groups. The effect sizes of both tests were somewhat small despite the significant differences between the two age groups on both dot-dot and dot-number observed in Table 2. It is plausible that ANS acuity, nonsymbolic, and basic symbolic numerical knowledge fully reach the developmental milestone on numerical competence at younger ages [85]. This follows previous findings that demonstrated the specific effects of ANS acuity and mapping precision between numeral notations and their corresponding magnitudes that are dominant only in preschool children [86]. The performance on the mental number line test significantly differed between 6-and 7-year-old children but the extent of discrepancy was small following the literature. However, the performance in the mental number line test explained a relatively small amount of variance in the SEM model compared to the numerical comparison tasks. Although young children can count objects and understand relationships between objects and cardinal numbers, the number line further requires an understanding of lengths between the numbers written below the intervals on the number line. Thus, the number line seems to be a difficult tool to master for children who are younger than 7 and 8 years [87].

There is still a lack of agreement on the relative importance of domain-specific precursors in the development of mathematical abilities [76]. The unique contribution of the present SEM findings is the differential associations between specific indicators of the domain-specific early mathematics and the number-specific EFs and the mathematical abilities from kindergarten through primary school. The importance of subitizing, approximation, and comparison as indexed by the dot-dot and dot-number comparison tests for mathematical abilities decreased as preschool children progressed through formal schooling. Nonetheless, the symbolic and exact understanding of numerical concepts as measured by the number comparison and the mental number line tests was prioritized for the mathematical abilities with successive grades. Furthermore, the mathematical abilities were more dependent on both the domain-specific early mathematics $(0.67$ vs. 0.76$)$ and the number-specific EFs (0.69 vs. 0.77) in older children. The mathematical problems will call upon a crucial process of detecting and assessing critical features of number sense [61] and involving inhibition and shifting of information [88]. A strong influence of both the domain-specific early mathematics and the numberspecific EFs in older children may reflect the increasingly demanding role of shifting and inhibition capacities with age (e.g., [40, 89]).

Another main finding is that the relative importance of the domain-specific early mathematics and the number-specific EFs that are similar in size in relation to the mathematical abilities of 6-year-old children. However, the number-specific EFs showed a stronger relationship with mathematical abilities than the domain-specific early mathematics for 7-year-old children. Indeed, children are required to map and combine the different Arabic numerals and symbols onto the corresponding quantities and then compare them with the target number of each item to master mathematical competencies as measured by the number sets and the numerical operation tests. Although the present study supports the previous findings that quantity representation or ability to map quantities and magnitudes with symbols was associated with the mathematical abilities (e.g., 1, 86, 91), our results highlight the stronger association among the domainspecific early mathematics, the EFs in a numerical context, and the mathematical abilities at the beginning of formal schooling. The older children may learn schooltaught mathematics, providing them with knowledge on symbol systems and procedural tools. Accordingly, to achieve mathematical calculations, the performances of EFs in a numerical context were improved in older children.

Furthermore, a more efficient supporting system or the EFs may be required to encourage the acquisition of existing early mathematical abilities and arithmetical capabilities with cumulative knowledge of symbol systems and strategy choices and discoveries in older children [90, 91]. In this view, apart from better knowledge on domain-specific early mathematics, primary school children have to rely directly on the EF subcomponents to some extent. In this case, solving mathematical problems allows the child to select relevant information or strategies, inhibiting numerical information already processed but no longer relevant. Cognitive flexibility also allows the child to switch from one strategy to another, transforming or substituting the no-longer relevant information with a new one [92-94].

Nonetheless, this study also possesses several noteworthy limitations. Given the strong link between working memory and IQ, although no children with LD and ADHD were found, the present study lacks control over children's IQ scores. Accordingly, a cautious interpretation of the finding must be considered. In addition, working memory was found to be the second EF component to emerges, after inhibitory ability and before shifting ability, during preschool ages and it is also regarded as a tool of learning (e.g., $[96,97])$. Specifically, a weakness in working memory has been documented in children with 
dyscalculia (e.g., [98, 99]). Thus, further study should investigate working memory as an EF component in numerical domain.

Moreover, the weak correlation among the mental number line and other variables in the same construct may additionally stem from the issues of the test format and the scoring method. A further limitation of this study is that children could have made their comparisons on the basis of continuous extent rather than the number for nonsymbolic stimuli $[95,96]$. Future work needs to consider this stimulus issue for children at this young age.

For practice reasons and practices, the paper-and-pencil based tests were suitable for our settings in terms of distribution and administration of the tests. However, the response time could reflect the automatization during numerical processing of both mathematical and executive functioning skills of the young age [99]. Thus, the selection of the computerized version of these mathematical cognition tasks should also be considered for further studies because the computer-based tasks may offer several sophisticated parameters (e.g., response accuracy, response time, and difference scores), standardized test administration procedures, automatic scoring, and instant feedback for children and teachers [97-100].

The current study did not compare the relative effects of the domain-specific early mathematics, the numberspecific EFs, and the general EFs on mathematical abilities. Further studies should specifically compare common and unique roles of domain-general vs. domain-specific EF on mathematical development. The present findings provide a strong motivation to delineate these factors. Finally, a longitudinal study is needed to support the current findings in regards to the differential effects of the domain-specific early mathematics and the number-specific EFs on the mathematical abilities.

\section{Conclusion}

The present study yielded two key findings. First, 7-yearold children outperformed 6-year-old children in the overall measures of the domain-specific early mathematics and the number-specific EFs, especially for more sophisticated numerical knowledge and EF subcomponents, namely, symbolic numerical magnitude representations as indexed by the number comparison and the mental number line tests and the numerical inhibitory and shifting abilities as measured by the numerical inhibition and shifting tests. Second, both the domainspecific early mathematics and the number-specific EFs comparably and significantly related to the mathematical abilities for 6- and 7-year-old children, but the domainspecific early mathematics and the number-specific EFs were dominant concerning the mathematical abilities for 7-year-old children.

\begin{abstract}
Abbreviations
ANS: Approximate Number System; EFs: Executive Functions; LD: Learning Difficulties; ADHD: Attention Deficit Hypoeractivity Disorder; PAE: Percent Absolute Error; MANOVA: Multiple Analysis of Variance; SEM: Structural Equation Modeling; GFI: Goodness of Fit Index; VIF: Value Inflation Factor; LTM: Long-Term Memory.
\end{abstract}

\section{Acknowledgements}

None.

\section{Authors' contributions}

PW and RCK contributed to the first draft of the manuscript. PW and RCK designed the methodology and created the models. PW conducted the formal analysis. Both authors read and approved the final manuscript.

\section{Funding}

This work is part of the project entitled 'A neuropsychological investigation and development of a cognitive-based screening tool in children at risk of mathematical learning disability' and was supported by National Research Council of Thailand (NRCT54/2550) and Newton Mobility Grant 2017 RD1 (NG170110).

\section{Availability of data and materials}

The dataset for the current study is available from the corresponding author on reasonable request.

\section{Declarations}

\section{Ethics approval and consent to participate}

The study was approved by the Burapha University Research Ethics Committee (BUU 6200/01533). All methods were conducted in accordance with the Good Clinical Practice (GCP) guidelines and the Declaration of Helsinki. Written informed consent was obtained signed by parents for all participants.

\section{Consent for publication}

Not applicable.

\section{Competing interests}

On behalf of the authors, the corresponding author states that there are no competing interests.

\section{Author details}

${ }^{1}$ Cognitive Science and Innovation Research Unit, College of Research Methodology and Cognitive Science, Burapha University, Saen Suk, Thailand. ${ }^{2}$ Department of Experimental Psychology, University of Oxford, Oxford, UK.

Received: 30 April 2021 Accepted: 4 February 2022

Published online: 11 February 2022

\footnotetext{
References

1. Brankaer C, Ghesquière P, De Smedt B. Symbolic magnitude processing in elementary school children: a group administered paper-and-pencil measure (SYMP Test). Behav Res Methods. 2017:49(4):1361-73.

2. Landerl K. Neurocognitive perspective on numerical development. In: Fritz A, Haase VG, Räsänen P, editors. International handbook of mathematical learning difficulties: from the laboratory to the classroom. Cham: Springer:2019 p. 9-24.

3. Reyna VF, Brainerd CJ. The importance of mathematics in health and human judgment: numeracy, risk communication, and medical decision making. Learn Individ Differ. 2007;17(2):147-59.

4. Butterworth B. Forward. In: Fritz A, Haase VG, Räsänen P, editors. International handbook of mathematical learning difficulties: from the laboratory to the classroom. Cham: Springer; 2019.

5. Ritchie SJ, Bates TC. Enduring links from childhood mathematics and reading achievement to adult socioeconomic status. Psychol Sci. 2013:24(7):1301-8.
} 
6. Butterworth B, Varma S, Laurillard D. Dyscalculia: from brain to education. Science. 2011;332(6033):1049-53.

7. Cantlon JF, Brannon EM, Carter EJ, Pelphrey KA. Functional imaging of numerical processing in adults and 4-y-old children. PLOS Biol. 2006;4(5): e125.

8. Carvalho MRS, Haase VG. Genetics of Dyscalculia 2. In search of endophenotypes. In: Fritz A, Haase VG, Räsänen P, editors. International handbook of mathematical learning difficulties: from the laboratory to the classroom. Cham: Springer; 2019. p. 345-65.

9. Cohen Kadosh R, Dowker A. The Oxford handbook of numerical cognition. New York: Oxford University Press; 2014

10. De Smedt B, Noël M-P, Gilmore C, Ansari D. How do symbolic and nonsymbolic numerical magnitude processing skills relate to individual differences in children's mathematical skills? A review of evidence from brain and behavior. Trends Neurosci Educ. 2013;2(2):48-55.

11. Rinaldi L, Girelli L. A place for zero in the brain. Trends Cogn Sci. 2016;20(8):563-4.

12. Feigenson L, Dehaene S, Spelke E. Core systems of number. Trends Cogn Sci. 2004;8(7):307-14.

13. Starr A, Libertus ME, Brannon EM. Number sense in infancy predicts mathematical abilities in childhood. Proc Natl Acad Sci. 2013;110:18116-181120.

14. Libertus ME, Odic D, Feigenson L, Halberda J. The precision of mapping between number words and the approximate number system predicts children's formal math abilities. J Exp Child Psychol. 2016;150:207-26.

15. Odic D, Le Corre M, Halberda J. Children's mappings between number words and the approximate number system. Cognition. 2015;138:102-21.

16. Siegler RS, Lortie-Forgues $\mathrm{H}$. An integrative theory of numerical development. Child Dev Perspect. 2014;8(3):144-50.

17. Fias $W$, Verguts $T$. The mental number line: exact and approximate. Trends Cogn Sci. 2004;8(10):447-8 (author reply 8-9).

18. von Aster MG, Shalev RS. Number development and developmental dyscalculia. Dev Med Child Neurol. 2007;49(11):868-73.

19. Wolf $S, M c C o y D C$. The role of executive function and social-emotional skills in the development of literacy and numeracy during preschool: a cross-lagged longitudinal study. Dev Sci. 2019;22(4): e12800.

20. Berteletti I, Lucangeli D, Piazza M, Dehaene S, Zorzi M. Numerical estimation in preschoolers. Dev Psychol. 2010;46(2):545-51.

21. Siegler RS, Booth JL. Development of numerical estimation in young children. Child Dev. 2004;75(2):428-44.

22. Soltész F, Goswami U, White S, Szűcs D. Executive function effects and numerical development in children: behavioural and ERP evidence from a numerical Stroop paradigm. Learn Individ Differ. 2011;21(6):662-71.

23. Best JR, Miller PH. A developmental perspective on executive function. Child Dev. 2010;81(6):1641-60.

24. Best JR, Miller PH, Jones LL. Executive functions after age 5 : changes and correlates. Dev Rev. 2009:29(3):180-200.

25. Miyake A, Friedman NP. The nature and organization of individual differences in executive functions: four general conclusions. Curr Dir Psychol Sci. 2012;21(1):8-14

26. Röthlisberger M, Neuenschwander R, Cimeli P. Michel E, Roebers CM. Improving executive functions in 5 - and 6 -year-olds: Evaluation of a small group intervention in prekindergarten and kindergarten children. Infant Child Dev. 2012;21(4):411-29.

27. Kolkman ME, Hoijtink HJA, Kroesbergen EH, Leseman PPM. The role of executive functions in numerical magnitude skills. Learn Individ Differ. 2013;24:145-51

28. Schmitt SA, Geldhof GJ, Purpura DJ, Duncan R, McClelland MM. Examining the relations between executive function, math, and literacy during the transition to kindergarten: a multi-analytic approach. J Educ Psychol. 2017;109(8):1120-40.

29. Geary DC, van Marle K. Young children's core symbolic and nonsymbolic quantitative knowledge in the prediction of later mathematics achievement. Dev Psychol. 2016:52(12):2130-44.

30. Prager EO, Sera MD, Carlson SM. Executive function and magnitude skills in preschool children. J Exp Child Psychol. 2016;147:126-39.

31. Verdine BN, Irwin CM, Golinkoff RM, Hirsh-Pasek K. Contributions of executive function and spatial skills to preschool mathematics achievement. J Exp Child Psychol. 2014;126:37-51.
32. Gashaj V Oberer N, Mast FW, Roebers CM. The relation between executive functions, fine motor skills, and basic numerical skills and their relevance for later mathematics achievement. Early Educ Dev. 2019;30(7):913-26.

33. Hawes Z, Moss J, Caswell B, Seo J, Ansari D. Relations between numerical, spatial, and executive function skills and mathematics achievement: a latent-variable approach. Cogn Psychol. 2019:109:68-90.

34. Wilkey ED, Pollack C, Price GR. Dyscalculia and typical math achievement are associated with individual differences in number-specific executive function. Child Dev. 2020;91(2):596-619.

35. Bull R, Scerif G. Executive functioning as a predictor of children's mathematics ability: inhibition, switching, and working memory. Dev Neuropsychol. 2001;19(3):273-93.

36. Garon N, Bryson SE, Smith IM. Executive function in preschoolers: a review using an integrative framework. Psychol Bull. 2008;134(1):31-60.

37. Davidson MC, Amso D, Anderson LC, Diamond A. Development of cognitive control and executive functions from 4 to 13 years: evidence from manipulations of memory, inhibition, and task switching. Neuropsychologia. 2006;44(11):2037-78.

38. McKenna R, Rushe T. Woodcock KA. Informing the structure of executive function in children: a meta-analysis of functional neuroimaging data. Front Hum Neurosci. 2017;11:154.

39. Anderson P. Assessment and development of executive function (EF) during childhood. Child Neuropsychol. 2002;8(2):71-82.

40. Fuhs MW, Tavassolie N, Wang Y, Bartek V, Sheeks NA, Gunderson EA. Children's flexible attention to numerical and spatial magnitudes in early childhood. J Cogn Dev. 2021:22(1):22-47.

41. Schmitt SA, McClelland MM, Tominey SL, Acock AC. Strengthening school readiness for Head Start children: evaluation of a self-regulation intervention. Early Child Res Q. 2015;30:20-31.

42. Spiegel JA, Goodrich JM, Morris BM, Osborne CM, Lonigan CJ. Relations between executive functions and academic outcomes in elementary school children: a meta-analysis. Psychol Bull. 2021;147(4):329-51.

43. Miyake A, Friedman NP, Emerson MJ, Witzki AH, Howerter A, Wager TD. The unity and diversity of executive functions and their contributions to complex"frontal lobe" tasks: a latent variable analysis. Cogn Psychol. 2000;41(1):49-100.

44. Ribner A, Moeller K, Willoughby M, Blair C. Cognitive abilities and mathematical competencies at school entry. Mind Brain Educ. 2018;12(4):175-85.

45. Harvey HA, Miller GE. Executive function skills, early mathematics, and vocabulary in head start preschool children. Early Educ Dev. 2017;28(3):290-307.

46. Schmerold K, Bock A, Peterson M, Leaf B, Vennergrund K, Pasnak R. The relations between patterning, executive function, and mathematics. J Psychol. 2017;151(2):207-28.

47. Magalhães S, Carneiro L, Limpo T, Filipe M. Executive functions predict literacy and mathematics achievements: the unique contribution of cognitive flexibility in grades 2,4 , and 6 . Child Neuropsychol. 2020;26(7):934-52.

48. Espy KA, McDiarmid MM, Cwik MF, Stalets MM, Hamby A, Senn TE. The contribution of executive functions to emergent mathematic skills in preschool children. Dev Neuropsychol. 2004;26(1):465-86.

49. Pellizzoni S, Apuzzo GM, De Vita C, Agostini T, Ambrosini M, Passolunghi MC. Exploring EFs and math abilities in highly deprived contexts. Front Psychol. 2020;11:383.

50. Melby-Lervåg M, Hulme C. Is working memory training effective? A meta-analytic review. Dev Psychol. 2013;49(2):270-91.

51. Viterbori P, Usai MC, Traverso L, De Franchis V. How preschool executive functioning predicts several aspects of math achievement in Grades 1 and 3: a longitudinal study. J Exp Child Psychol. 2015;140:38-55.

52. Traverso L, Viterbori P, Usai MC. Effectiveness of an executive function training in italian preschool educational services and far transfer effects to pre-academic skills. Front Psychol. 2019:10:2053.

53. Scionti N, Cavallero M, Zogmaister C, Marzocchi GM. Is cognitive training effective for improving executive functions in preschoolers? A systematic review and meta-analysis. Front Psychol. 2020;10:2812.

54. Diamond A, Ling DS. Conclusions about interventions, programs, and approaches for improving executive functions that appear justified and those that, despite much hype, do not. Dev Cogn Neurosci. 2016:18:34-48. 
55. Gilmore C, Cragg L. Chapter 14-the role of executive function skills in the development of children's mathematical competencies. In: Henik A, Fias W, editors. Heterogeneity of function in numerical cognition. Cambridge: Academic Press; 2018. p. 263-86.

56. Coolen I, Merkley R, Ansari D, Dove E, Dowker A, Mills A, et al. Domain-general and domain-specific influences on emerging numerical cognition: contrasting uni-and bidirectional prediction models. Cognition. 2021;215: 104816.

57. Fuhs MW, Nesbitt KT, O'Rear CD. Approximate number system task performance: associations with domain-general and domain-specific cognitive skills in young children. J Numer Cognit. 2018;4(3):590-612.

58. Gilmore C, Keeble S, Richardson S, Cragg L. The role of cognitive inhibition in different components of arithmetic. ZDM Math Educ. 2015;47(5):771-82

59. Braeuning D, Hornung C, Hoffmann D, Lambert K, Ugen S, Fischbach A, et al. Long-term relevance and interrelation of symbolic and non-symbolic abilities in mathematical-numerical development: evidence from largescale assessment data. Cognit Dev. 2021;58: 101008.

60. Scalise NR, Ramani GB. Symbolic magnitude understanding predicts preschoolers'later addition skills. J Cognit Dev. 2021;22:185-202.

61. Geary DC, Bailey DH, Hoard MK. Predicting mathematical achievement and mathematical learning disability with a simple screening tool: the number sets test. J Psychoeduc Assess. 2009;27(3):265-79.

62. Arán Filippetti V, Richaud MC. A structural equation modeling of executive functions, IQ and mathematical skills in primary students: differential effects on number production, mental calculus and arithmetical problems. Child Neuropsychol. 2017;23(7):864-88.

63. Wei W, Guo L, Georgiou GK, Tavouktsoglou A, Deng C. Different subcomponents of executive functioning predict different growth parameters in mathematics: evidence from a 4-year longitudinal study with Chinese children. Front Psychol. 2018;9:1037.

64. Geary DC. Cognitive predictors of achievement growth in mathematics: a 5-year longitudinal study. Dev Psychol. 2011;47(6):1539-52.

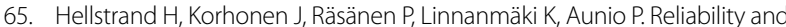
validity evidence of the early numeracy test for identifying children at risk for mathematical learning difficulties. Int J Educ Res. 2020;102: 101580

66. Gray SA, Reeve RA. Preschoolers'Dot Enumeration Abilities Are Markers of Their Arithmetic Competence. PLoS ONE. 2014;9(4): e94428.

67. Huber S, Klein E, Moeller K, Willmes K. Spatial-numerical and ordinal positional associations coexist in parallel. Front Psychol. 2016;7:438.

68. Schneider M, Merz S, Stricker J, De Smedt B, Torbeyns J, Verschaffel L, et al. Associations of number line estimation with mathematical competence: a meta-analysis. Child Dev. 2018;89(5):1467-84.

69. Cohen Kadosh R, Henik A, Rubinsten O. Are Arabic and verbal numbers processed in different ways? J Exp Psychol Learn Mem Cogn. 2008;34(6):1377-91.

70. Dadon G, Henik A. Adjustment of control in the numerical Stroop task. Mem Cognit. 2017;45(6):891-902.

71. Henik A, Tzelgov J. Is three greater than five: the relation between physical and semantic size in comparison tasks. Mem Cognit. 1982;10(4):389-95.

72. Buttelmann F,Karbach J. Development and plasticity of cognitive flexibility in early and middle childhood. Front Psychol. 2017;8:1040.

73. Wongupparaj P, Kumari V, Morris RG. The relation between a multicomponent working memory and intelligence: the roles of central executive and short-term storage functions. Intelligence. 2015;53:166-80.

74. Sauseng P, Klimesch W, Freunberger R, Pecherstorfer T, Hanslmayr S, Doppelmayr M. Relevance of EEG alpha and theta oscillations during task switching. Exp Brain Res. 2006;170(3):295-301.

75. Bjork IM, Bowyer-Crane C. Cognitive skills used to solve mathematical word problems and numerical operations: a study of 6- to 7-year-old children. Eur J Psychol Educ. 2013;28(4):1345-60.

76. Passolunghi MC, Costa HM. Working memory and mathematical learning. In: Fritz A, Hase V, Räsänen P, editors. International handbook of mathematical learning difficulties: from the laboratory to the classroom. Cham: Springer; 2019. p. 407-21.

77. Kelley K, Preacher KJ. On effect size. Psychol Methods. 2012;17(2):137-52.

78. Lakens D. Calculating and reporting effect sizes to facilitate cumulative science: a practical primer for t-tests and ANOVAs. Front Psychol. 2013;4:863.

79. Arbuckle JL. SPSS Amos. 26.0 ed. Chicago: IBM SPSS; 2019.

80. Fan Y, Chen J, Shirkey G, John R, Wu SR, Park H, et al. Applications of structural equation modeling (SEM) in ecological studies: an updated review. Ecol Process. 2016;5(1):19.
81. Schermelleh-Engel K, Moosbrugger H, Müller H. Evaluating the fit of structural equation models: tests of significance and descriptive goodness-offit measures. Methods Psychol Res. 2003:8(2):23-74.

82. Gao S, Mokhtarian PL, Johnston RA. Nonnormality of data in structural equation models. Transp Res Rec. 2008;2082(1):116-24.

83. Montgomery DC, Peck EA, Vining GG. Introduction to linear regression analysis. 3rd ed. New York: Wiley; 2001.

84. Göbel SM,Watson SE, Lervåg A, HulmeC.Children's arithmetic development: it is number knowledge, not the approximate number sense, that counts. Psychol Sci. 2014;25(3):789-98.

85. van Marle K, Chu FW, LiY, Geary DC. Acuity of the approximate number system and preschoolers' quantitative development. Dev Sci. 2014:17(4):492-505.

86. Gimbert F, Camos V, Gentaz E, Mazens K. What predicts mathematics achievement? Developmental change in 5- and 7-year-old children. J Exp Child Psychol. 2019;178:104-20.

87. Fuson KC. Relating math words, visual images, and math symbols for understanding and competence. Int J Disabil Dev Educ. 2019;66(2):119-32.

88. Daucourt MC, Schatschneider C, Connor CM, Al Otaiba S, Hart SA. Inhibition, updating working memory, and shifting predict reading disability symptoms in a hybrid model: project KIDS. Front Psychol. 2018;9:238.

89. Park J, Li R, Brannon EM. Neural connectivity patterns underlying symbolic number processing indicate mathematical achievement in children. Dev Sci. 2014;17(2):187-202.

90. Shrager J, Siegler RS. SCADS: a model of children's strategy choices and strategy discoveries. Psychol Sci. 1998;9(5):405-10.

91. Siegler RS, Crowley K. The microgenetic method. A direct means for studying cognitive development. Am Psychol. 1991;46(6):606-20.

92. Ecker UK, Lewandowsky S, Oberauer K, Chee AE. The components of working memory updating: an experimental decomposition and individual differences. J Exp Psychol Learn Mem Cogn. 2010;36(1):170-89.

93. Passolunghi MC, Pazzaglia F. Individual differences in memory updating in relation to arithmetic problem solving. Learn Individ Differ. 2004;14(4):219-30.

94. Passolunghi MC, Siegel LS. Working memory and access to numerical information in children with disability in mathematics. J Exp Child Psychol. 2004;88(4):348-67.

95. Gebuis T, Reynvoet B. The interplay between nonsymbolic number and its continuous visual properties. J Exp Psychol Gen. 2012;141(4):642-8.

96. Gevers W, Kadosh RC, Gebuis T. Chapter 18 - sensory integration theory: an alternative to the approximate number system. In: Henik A, editor. Continuous issues in numerical cognition. San Diego: Academic Press; 2016. p. 405-18.

97. Hassler HallstedtM,Ghaderi A.Tablets instead of paper-based tests foryoung children? Comparability between paper and tablet versions of the mathematical Heidelberger Rechen Test 1-4. Educ Assess. 2018;23(3):195-210.

98. Blumenthal S, Blumenthal Y. Tablet or paper and pen? Examining mode effects on german elementary school students' computation skills with curriculum-based measurements. Int J Educ Methodol. 2020;6(4):669-80.

99. Landerl K. Development of numerical processing in children with typical and dyscalculic arithmetic skills-a longitudinal study. Front Psychol. 2013:4:459.

100. Balzer C.Computer-Based Assessments. Office of Assessment, Research, and Data Analysis; 2010

\section{Publisher's Note}

Springer Nature remains neutral with regard to jurisdictional claims in published maps and institutional affiliations. 